\title{
Frequency of Eating and All-Cause Mortality: A Systematic Review
}

\author{
2020 Dietary Guidelines Advisory Committee, \\ Frequency of Eating Subcommittee \\ Published date: July 15, 2020
}

Nutrition Evidence Systematic Review

Center for Nutrition Policy and Promotion

Food and Nutrition Service

U.S. Department of Agriculture

Braddock Metro Center II

1320 Braddock Place

Alexandria, Virginia 22314 
This systematic review was conducted by the 2020 Dietary Guidelines Advisory Committee in collaboration with the Nutrition Evidence Systematic Review (NESR) team at the Center for Nutrition Policy and Promotion, Food and Nutrition Service, U.S. Department of Agriculture (USDA). All systematic reviews from the 2020 Advisory Committee Project are available on the NESR website: https://nesr.usda.gov/2020-dietaryguidelines-advisory-committee-systematic-reviews.

Conclusion statements drawn as part of this systematic review describe the state of science related to the specific question examined. Conclusion statements do not draw implications, and should not be interpreted as dietary guidance. This portfolio provides the complete documentation for this systematic review. A summary of this review is included in the 2020 Advisory Committee's Scientific Report available at www.DietaryGuidelines.gov.

The contents of this document may be used and reprinted without permission. Endorsements by NESR, the Center for Nutrition Policy and Promotion, the Food and Nutrition Service, or the USDA of derivative products developed from this work may not be stated or implied.

Suggested citation for this systematic review: 2020 Dietary Guidelines Advisory Committee and Nutrition Evidence Systematic Review Team. Frequency of Eating and All-Cause Mortality: A Systematic Review. 2020 Dietary Guidelines Advisory Committee Project. Alexandria, VA: U.S. Department of Agriculture, Food and Nutrition Service, Center for Nutrition Policy and Promotion, July 2020. Available at: https://nesr.usda.gov/2020-dietary-guidelines-advisory-committee-systematic-reviews.

Related citation: Dietary Guidelines Advisory Committee. 2020. Scientific Report of the 2020 Dietary Guidelines Advisory Committee: Advisory Report to the Secretary of Agriculture and the Secretary of Health and Human Services. U.S. Department of Agriculture, Agricultural Research Service, Washington, DC.

In accordance with Federal civil rights law and USDA civil rights regulations and policies, the USDA, its Agencies, offices, and employees, and institutions participating in or administering USDA programs are prohibited from discriminating based on race, color, national origin, religion, sex, gender identity (including gender expression), sexual orientation, disability, age, marital status, family/parental status, income derived from a public assistance program, political beliefs, or reprisal or retaliation for prior civil rights activity, in any program or activity conducted or funded by USDA (not all bases apply to all programs). Remedies and complaint filing deadlines vary by program or incident.

Persons with disabilities who require alternative means of communication for program information (e.g., Braille, large print, audiotape, American Sign Language, etc.) should contact the responsible Agency or USDA's TARGET Center at (202) 720-2600 (voice and TTY) or contact USDA through the Federal Relay Service at (800) 877-8339. Additionally, program information may be made available in languages other than English.

To file a program discrimination complaint, complete the USDA Program Discrimination Complaint Form, AD3027, found online at How to File a Program Discrimination Complaint and at any USDA office or write a letter addressed to USDA and provide in the letter all of the information requested in the form. To request a copy of the complaint form, call (866) 632-9992. Submit your completed form or letter to USDA by: (1) mail: U.S. Department of Agriculture, Office of the Assistant Secretary for Civil Rights, 1400 Independence Avenue, SW, Washington, D.C. 20250-9410; (2) fax: (202) 690-7442; or (3) email: program.intake@usda.gov.

USDA is an equal opportunity provider, employer, and lender. 


\section{ACKNOWLEDGEMENTS}

Frequency of Eating Subcommittee:

- Steven Heymsfield, MD, Louisiana State University, Pennington Biomedical Research Center, Subcommittee Chair

- Carol Boushey, PhD, MPH, RD, University of Hawaii

- Heather Leidy, PhD, University of Texas at Austin

- Richard Mattes, PhD, MPH, RD, Purdue University

- Ronald Kleinman, MD, Massachusetts General Hospital, Harvard Medical School, Vice-Chair of the 2020 Dietary Guidelines Advisory Committee

\section{Nutrition Evidence Systematic Review (NESR) Team:}

- Emily Callahan, MS, Analyst, Office of Nutrition Guidance and Analysis (ONGA), Center for Nutrition Policy and Promotion (CNPP), Food and Nutrition Service (FNS), U.S. Department of Agriculture (USDA)

- Gisela Butera, MLIS, MEd, Systematic Review Librarian, Panum Group ${ }^{i}$

- Nancy Terry, MLS, Biomedical Librarian, National Institutes of Health (NIH) Library, U.S. Department of Health and Human Services (HHS)

- Julie Obbagy, PhD, RD, Project Lead, ONGA, CNPP, FNS, USDA

\section{Federal Liaisons:}

- Ashley Vargas, PhD, MPH, RDN, FAND, Eunice Kennedy Shriver National Institute of Child Health and Human Development, NIH, HHS

- Meghan Adler, MS, RD, FAND, ONGA, CNPP, FNS, USDA

- Rebecca Maclsaac, MS, RD, Division of Prevention Science (DPS), Office of Disease Prevention and Health Promotion (ODPHP), Office of the Assistant Secretary for Health (OASH), HHS

- Julia Quam, MSPH, RDN, DPS, ODPHP, OASH, HHS

\section{Project Leadership:}

- Eve Essery Stoody, PhD, Designated Federal Officer and Director, ONGA, CNPP, FNS, USDA

- Janet de Jesus, MS, RD, Nutrition Advisor, ODPHP, OASH, HHS

- Colette Rihane, MS, RD, Director, ONGA, CNPP, FNS, USDA (through October 2019)

USDA and HHS implemented a process to identify topics and scientific questions to be examined by the 2020 Dietary Guidelines Advisory Committee. The Committee conducted its review of evidence in subcommittees for discussion by the full Committee during its public meetings. The role of the Committee members involved establishing all aspects of the protocol, which presented the plan for how they would examine the scientific evidence, including the inclusion and exclusion criteria; reviewing all studies that met the criteria they set; deliberating on the body of evidence for each question; and writing and grading the conclusion statements to be included in

i Under contract with the Food and Nutrition Service, United States Department of Agriculture. 
the scientific report the 2020 Committee submitted to USDA and HHS. The NESR team with assistance from Federal Liaisons and Project Leadership, supported the Committee by facilitating, executing, and documenting the work necessary to ensure the reviews were completed in accordance with NESR methodology. More information about the 2020 Dietary Guidelines Advisory Committee, including the process used to identify topics and questions, can be found at www.DietaryGuidelines.gov. More information about NESR can be found at NESR.usda.gov.

FUNDING SOURCE: United States Department of Agriculture, Food and Nutrition Service, Center for Nutrition Policy and Promotion, Alexandria, VA 


\section{TABLE OF CONTENTS}

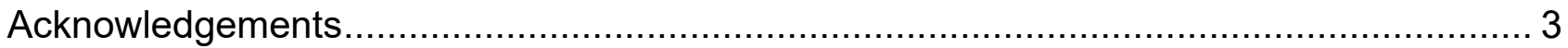



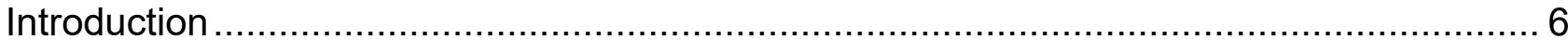

What is the relationship between the frequency of eating and all-cause mortality? ........... 8

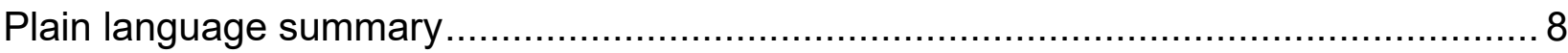



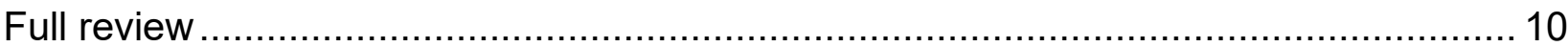

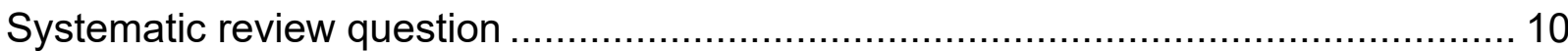

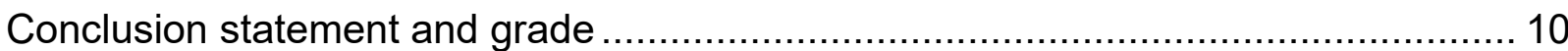

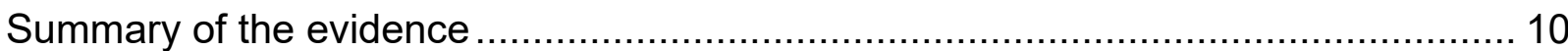



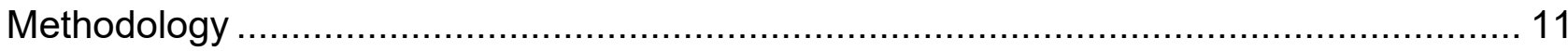



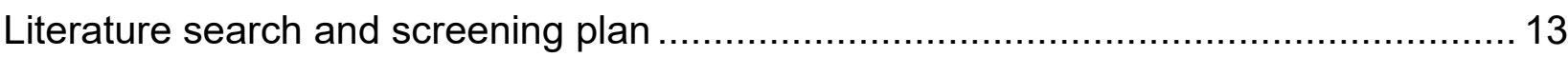

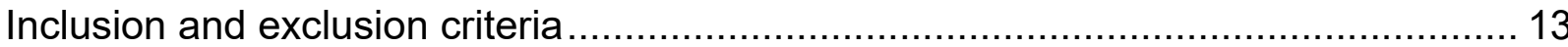

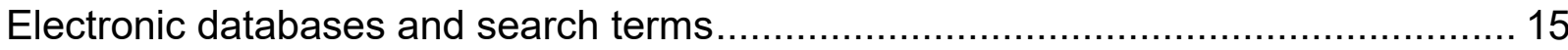

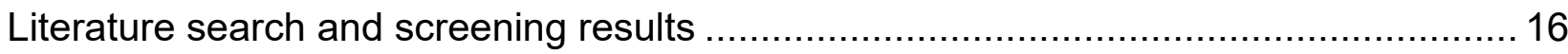

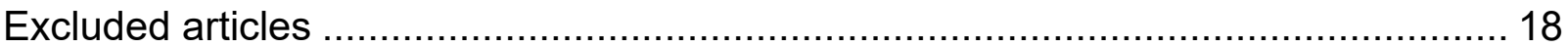

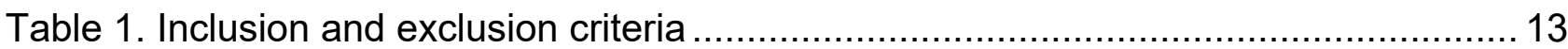

Table 2. Articles excluded after full text screening with rationale for exclusion................ 18

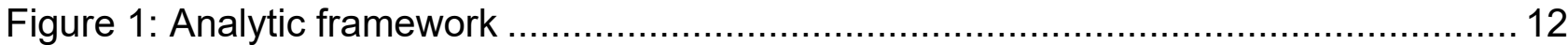

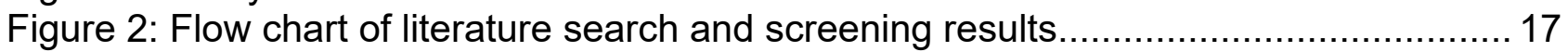


This document describes a systematic review conducted to answer the following question: What is the relationship between the frequency of eating and all-cause mortality? This systematic review was conducted by the 2020 Dietary Guidelines Advisory Committee, supported by USDA's Nutrition Evidence Systematic Review (NESR).

More information about the 2020 Dietary Guidelines Advisory Committee is available at the following website: www.DietaryGuidelines.gov.

NESR specializes in conducting food- and nutrition-related systematic reviews using a rigorous, protocol-driven methodology. More information about NESR is available at the following website: NESR.usda.gov.

NESR's systematic review methodology involves developing a protocol, searching for and selecting studies, extracting data from and assessing the risk of bias of each included study, synthesizing the evidence, developing conclusion statements, grading the evidence underlying the conclusion statements, and recommending future research. A detailed description of the systematic reviews conducted for the 2020 Dietary Guidelines Advisory Committee, including information about methodology, is available on the NESR website: https://nesr.usda.gov/2020-dietary-guidelines-advisory-committee-systematic-reviews. In addition, starting on page 11, this document describes the final protocol as it was applied in the systematic review. A description of and rationale for modifications made to the protocol are described in the 2020 Dietary Guidelines Advisory Committee Report, Part D: Chapter 13. Frequency of Eating. 
List of abbreviations

\begin{tabular}{ll}
\hline Abbreviation & Full name \\
\hline CNPP & Center for Nutrition Policy and Promotion \\
\hline DPS & Division of Prevention Science \\
\hline FoE & Frequency of eating \\
\hline FNS & Food and Nutrition Service \\
\hline HHS & Health and Human Services \\
\hline NESR & Nutrition Evidence Systematic Review \\
\hline NIH & National Institute of Health \\
\hline ONGA & Office of Nutrition Guidance and Analysis \\
\hline USDA & United States Department of Agriculture \\
\hline
\end{tabular}




\section{PLAIN LANGUAGE SUMMARY}

What is the question?

- The question is: What is the relationship between the frequency of eating and allcause mortality?

What is the answer to the question?

- No evidence is available to determine the relationship between the frequency of eating and all-cause mortality

Why was this question asked?

- This important public health question was identified by the U.S. Departments of Agriculture (USDA) and Health and Human Services (HHS) to be examined by the 2020 Dietary Guidelines Advisory Committee.

How was this question answered?

- The 2020 Dietary Guidelines Advisory Committee, Frequency of Eating Subcommittee conducted a systematic review to answer this question with support from the Nutrition Evidence Systematic Review (NESR) team.

- Frequency of eating was defined as the number of daily eating occasions.

What is the population of interest?

- The population of interest was generally healthy children through older adults (ages 2 and older).

What evidence was found?

- This review identified 0 studies that met the inclusion criteria.

How up-to-date is this systematic review?

- This review searched for studies from January, 2000 to June, 2019. 


\section{TECHNICAL ABSTRACT}

\section{Background}

- This important public health question was identified by the U.S. Departments of Agriculture (USDA) and Health and Human Services (HHS) to be examined by the 2020 Dietary Guidelines Advisory Committee.

- The 2020 Dietary Guidelines Advisory Committee, Frequency of Eating Subcommittee conducted a systematic review to answer this question with support from the Nutrition Evidence Systematic Review (NESR) team.

- The goal of this systematic review was to examine the following question: What is the relationship between the frequency of eating and all-cause mortality?

\section{Conclusion statement and grade}

- No evidence is available to determine the relationship between the frequency of eating and all-cause mortality. (Grade: Grade Not Assignable)

\section{Methods}

- A literature search was conducted using 3 databases (PubMed, Cochrane, and Embase) to identify articles that evaluated an intervention or exposure of the frequency of eating and the outcome of all-cause mortality. A manual search was also conducted to identify articles that may not have been included in the electronic databases searched. Articles were screened by two authors independently for inclusion based on pre-determined criteria.

- Because no articles were identified in the literature search, this systematic review did not involve data extraction, risk of bias assessment, or evidence synthesis. However, a conclusion statement was developed, that acknowledged the absence of evidence to address this question. Since no evidence was available to answer this question, the strength of evidence could not be graded.

\section{Summary of the evidence}

- This systematic review was undertaken to examine the relationship between the frequency of eating and all-cause mortality.

- All-cause mortality was defined as the total number of deaths from all causes during a specific time-period.

- This review identified 0 studies published between January, 2000 and June, 2019 that met the inclusion criteria for this systematic review. 


\section{FULL REVIEW}

\section{Systematic review question}

What is the relationship between the frequency of eating and all-cause mortality?

\section{Conclusion statement and grade}

No evidence is available to determine the relationship between the frequency of eating and all-cause mortality. (Grade: Grade not assignable)

\section{Summary of the evidence}

- This systematic review was undertaken to examine the relationship between the frequency of eating and all-cause mortality.

- All-cause mortality was defined as the total number of deaths from all causes during a specific time-period.

- This review identified 0 studies published between January, 2000 and June, 2019 that met the inclusion criteria for this systematic review.

\section{Research recommendations}

- More controlled trials are needed that assess the frequency of eating and various outcomes.

- Future studies should develop a consistent definition of an ingestive event that includes eating and drinking and methods to quantify it.

- Future studies should document the frequency of water consumption.

- In future studies, collection of ingestive frequency data should:

- Report number of ingestive events across 24 hours.

- Collect a minimum of 3 days of ingestive event data on at least 2 discrete occasions to allow assessment of estimate reliability.

- Future studies should report information on food insecurity in relation to frequency of eating to allow isolation of voluntary versus involuntary eating frequency effects.

- Future research should report key confounders and other factors to be considered, such as:

- Sex, Age, Race/ethnicity, Habitual eating frequency, Smoking, Anthropometry, Socioeconomic status, Physical activity, Cultural practices, Total energy intake, Diet energy density, Energy state of the diet (restriction/surplus), Energy balance (total energy intake/total energy expenditure), Chrononutrition factors (time of day, (consistency of) habitual eating frequency, and duration between ingestive events and/or ingestive periods), Portion size, Macronutrient content, Location of eating occasion, Eating environment (who you eat with, work/school/exercise schedule), Holiday eating (seasonal), Sleep schedule (shift work), Secondary eating, Dentition, Hydration status, Pregnancy status, Pubertal status, Menopausal status, Biochemical changes 
The NESR team used its rigorous, protocol-driven methodology to support the 2020 Dietary Guidelines Advisory Committee in conducting this systematic review.

NESR's systematic review methodology involves:

- Developing a protocol,

- Searching for and selecting studies,

- Extracting data from and assessing the risk of bias of each included study,

- Synthesizing the evidence,

- Developing conclusion statements,

- Grading the evidence underlying the conclusion statements, and

- Recommending future research.

A detailed description of the methodology used in conducting this systematic review is available on the NESR website: https://nesr.usda.gov/2020-dietary-guidelines-advisory-committee-systematicreviews, and can be found in the 2020 Dietary Guidelines Advisory Committee Report, Part C: Methodology. .i Additional information about this systematic review, including a description of and rationale for any modifications made to the protocol can be found in the 2020 Dietary Guidelines Advisory Committee Report, Chapter 13. Frequency of Eating.

Below are details of the final protocol for the systematic review described herein, including the:

- Analytic framework

- Literature search and screening plan

- Literature search and screening results

\section{ANALYTIC FRAMEWORK}

The analytic framework (Figure 1) illustrates the overall scope of the systematic review, including the population, the interventions and/or exposures, comparators, and outcomes of interest. It also includes definitions of key terms and identifies key confounders considered in the systematic review. The inclusion and exclusion criteria that follow provide additional information about how parts of the analytic framework were defined and operationalized for the review.

ii Dietary Guidelines Advisory Committee. 2020. Scientific Report of the 2020 Dietary Guidelines Advisory Committee: Advisory Report to the Secretary of Agriculture and the Secretary of Health and Human Services. U.S. Department of Agriculture, Agricultural Research Service, Washington, DC. 


\section{Figure 1: Analytic framework}

Systematic review question: What is the relationship between the frequency of eating and all-cause mortality?

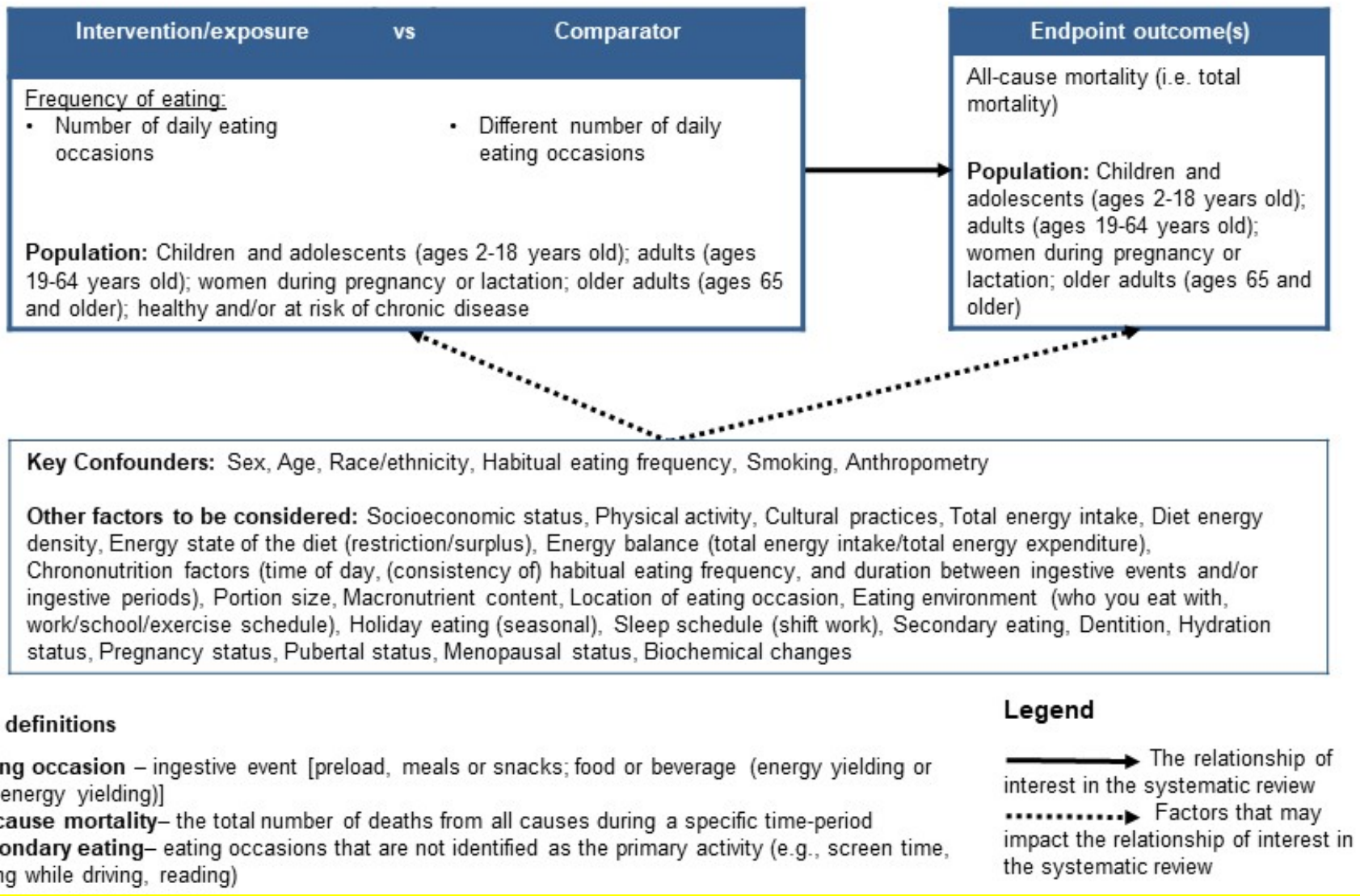




\section{LITERATURE SEARCH AND SCREENING PLAN}

\section{Inclusion and exclusion criteria}

This table provides the inclusion and exclusion criteria for the systematic review. The inclusion and exclusion criteria are the set of characteristics used to determine which articles identified in the literature search were included in or excluded from the systematic review.

\section{Table 1. Inclusion and exclusion criteria}

\begin{tabular}{|c|c|c|}
\hline Category & Inclusion Criteria & Exclusion Criteria \\
\hline Study design & $\begin{array}{l}\text { - Randomized controlled trials } \\
\text { - Non-randomized controlled trials, including quasi- } \\
\text { experimental and controlled before and after } \\
\text { studies } \\
\text { - } \quad \text { Prospective cohort studies } \\
\text { - } \quad \text { Retrospective cohort studies } \\
\text { - Nested case-control studies }\end{array}$ & $\begin{array}{l}\text { - Uncontrolled trials } \\
\text { - } \text { Case-control studies } \\
\text { - } \text { Cross-sectional studies } \\
\text { - } \quad \text { Uncontrolled before-and-after studies } \\
\text { - } \quad \text { Narrative reviews } \\
\text { - } \quad \text { Systematic reviews } \\
\text { - } \quad \text { Meta-analyses }\end{array}$ \\
\hline $\begin{array}{l}\text { Intervention/ } \\
\text { exposure }\end{array}$ & $\begin{array}{l}\text { Frequency of eating: } \\
\text { - Number of daily eating occasions }\end{array}$ & $\begin{array}{l}\text { - Studies that only examine frequency of } \\
\text { intake of a single food, beverage or category } \\
\text { of foods or beverages (i.e. frequency of milk } \\
\text { consumption, frequency of seafood } \\
\text { consumption) } \\
\text { - Studies that do not have eating occasions } \\
\text { across the day }\end{array}$ \\
\hline Comparator & - Different number of daily eating occasions & - N/A \\
\hline Outcomes & $\begin{array}{l}\text { - Studies that report all-cause mortality (i.e., total } \\
\text { mortality): the total number of deaths from all } \\
\text { causes during a specific time-period. }\end{array}$ & $\begin{array}{l}\text { - Studies that only report cause-specific } \\
\text { mortality (total number of deaths from a } \\
\text { specific disease, such as cardiovascular } \\
\text { disease or cancer) }\end{array}$ \\
\hline $\begin{array}{l}\text { Date of } \\
\text { publication }\end{array}$ & - January 2000 - June 2019 & $\begin{array}{l}\text { - Articles published prior to or after January } \\
2000 \text { - June } 2019\end{array}$ \\
\hline $\begin{array}{l}\text { Publication } \\
\text { status }\end{array}$ & - Articles published in peer-reviewed journals & $\begin{array}{l}\text { Articles that have not been peer-reviewed } \\
\text { and are not published in peer-reviewed } \\
\text { journals (e.g. unpublished data, manuscripts, } \\
\text { reports, abstracts, pre-prints, and conference } \\
\text { proceedings) }\end{array}$ \\
\hline $\begin{array}{l}\text { Language of } \\
\text { publication }\end{array}$ & - Articles published in English & $\begin{array}{l}\text { - Articles published in languages other than } \\
\text { English }\end{array}$ \\
\hline Country & $\begin{array}{l}\text { - Studies conducted in countries ranked as high or } \\
\text { very high human development }\end{array}$ & $\begin{array}{l}\text { - Studies conducted in countries ranked as } \\
\text { medium or lower human development }\end{array}$ \\
\hline
\end{tabular}

iii In order to determine the inclusion exclusion criteria for country, the Human Development classification was used. This classification is based on the Human Development Index (HDI) ranking from the year the study intervention 


\begin{tabular}{|c|c|c|}
\hline Category & Inclusion Criteria & Exclusion Criteria \\
\hline $\begin{array}{l}\text { Study } \\
\text { participants }\end{array}$ & $\begin{array}{ll}\text { - } & \text { Human participants } \\
\text { - } & \text { Males } \\
\text { - } & \text { Females } \\
\text { - } & \text { Females during pregnancy and the post-partum } \\
\text { period }\end{array}$ & $\begin{array}{l}\text { Non-human participants (i.e., } \\
\text { animals or in-vitro models) }\end{array}$ \\
\hline $\begin{array}{l}\text { Health status of } \\
\text { study } \\
\text { participants }\end{array}$ & $\begin{array}{l}\text { - Studies that enroll participants who are healthy } \\
\text { and/or at risk for chronic disease, including those } \\
\text { with obesity } \\
\text { - Studies that enroll some participants diagnosed } \\
\text { with a disease }\end{array}$ & $\begin{array}{l}\text { - Studies that exclusively enroll participants } \\
\text { diagnosed with a disease (for this criterion, } \\
\text { studies that exclusively enroll subjects with } \\
\text { obesity will be included) } \\
\text { - Studies that exclusively enroll subjects post } \\
\text { bariatric surgery }\end{array}$ \\
\hline $\begin{array}{l}\text { Eating } \\
\text { frequency data } \\
\text { collection for } \\
\text { intervention } \\
\text { studies }\end{array}$ & $\begin{array}{l}\text { - Data collection for eating frequency that occurs } \\
\text { on at least } 2 \text { occasions, including baseline and } \\
\text { during or after the intervention. } \\
\text { Each occasion encompasses a minimum } \\
\text { of } 3,24 \text {-hour periods or a questionnaire } \\
\text { that covers at least } 3 \text { days addressing } \\
\text { eating frequency. } \\
\text { (e.g., } 3,24-h \text { dietary recalls } \\
\text { reporting ingestive events) } \\
\text { (e.g., } 1 \text { eating frequency } \\
\text { questionnaire documenting } \\
\text { eating frequency for the past } \\
\text { month) }\end{array}$ & $\begin{array}{l}\text { Data collection for eating frequency that } \\
\text { occurs on fewer than } 2 \text { occasions, and } \\
\text { encompasses fewer than 3,24-hour periods }\end{array}$ \\
\hline $\begin{array}{l}\text { Eating } \\
\text { frequency data } \\
\text { collection for } \\
\text { observational } \\
\text { studies }\end{array}$ & $\begin{array}{l}\text { - Data collection for eating frequency that } \\
\text { encompasses a minimum of 3, 24-hour periods } \\
\circ \quad \text { (e.g., 3, 24-h dietary recalls reporting } \\
\text { each ingestive event) } \\
\circ \quad \begin{array}{l}\text { (e.g., } 1 \text { eating frequency questionnaire } \\
\text { documenting eating frequency for the } \\
\text { past month) }\end{array}\end{array}$ & $\begin{array}{l}\text { - Data collection for eating frequency that } \\
\text { encompasses fewer than 3,24-hour periods }\end{array}$ \\
\hline $\begin{array}{l}\text { Size of study } \\
\text { groups for } \\
\text { intervention } \\
\text { studies }\end{array}$ & $\begin{array}{l}\text { - } 15 \text { or greater participants for studies using within- } \\
\text { subject analyses, or } \\
\text { - } 30 \text { or greater participants for studies using } \\
\text { between-subject analysis, or } \\
\text { - } \quad \text { A power calculation included }\end{array}$ & $\begin{array}{l}\text { - Fewer than } 15 \text { participants for studies using } \\
\text { within-subject analyses, or } \\
\text { - Fewer than } 30 \text { participants for studies using } \\
\text { between-subject analysis, or } \\
\text { - No power calculation reported }\end{array}$ \\
\hline
\end{tabular}

occurred or data were collected (UN Development Program. HDI 1990-2017 HDRO calculations based on data from UNDESA (2017a), UNESCO Institute for Statistics (2018), United Nations Statistics Division (2018b), World Bank (2018b), Barro and Lee (2016) and IMF (2018). Available from: http://hdr.undp.org/en/data). If the study did not report the year in which the intervention occurred or data were collected, the HDI classification for the year of publication was applied. HDI values are available from 1980, and then from 1990 to present. If a study was conducted prior to 1990, the HDI classification from 1990 was applied. If a study was conducted in 2018 or 2019, the most current HDI classification was applied. When a country was not included in the HDI ranking, the current country classification from the World Bank was used instead (The World Bank. World Bank country and lending groups. Available from: https://datahelpdesk.worldbank.org/knowledgebase/articles/906519-world- country-and-lending-groups) 


\section{Electronic databases and search terms}

\section{PubMed}

- Provider: U.S. National Library of Medicine

- Date(s) searched: June 19, 2019

- Date range searched: January 1, 2000-June 19, 2019

- Search Terms:

\#1 - "frequency of eating" OR "eating frequency" OR "feeding frequency" OR "meals per day" OR beverage intake[tiab] OR "Meals"[Mesh] OR "meal frequency" OR "meal timing" OR "meal time" OR mealtime* OR daily meal* OR dinnertime* OR eating occasion* OR "snack frequency" OR "snacking frequency" OR "Fasting"[Mesh] OR "intermittent fasting" OR fasting diet $^{*}$ OR "alternate-day fasting" OR "meal skipping" OR "breakfast skipping" OR skipping breakfast* OR "drinking frequency" OR "infrequent consumption" OR "frequent consumption" OR "Feeding Behavior"[Mesh] OR feeding behavior*[tiab] OR eating pattern* OR time restricted feeding* OR meal profile* OR meal pattern* OR chrono-nutrition OR intermittent energy restriction* OR eating time*

\#2 - "Mortality"[Mesh] OR "mortality" [Subheading] OR mortality [tiab]

\#3 - (\#1 AND \#2)

\#4 - (\#1 AND \#2) NOT ("Animals"[Mesh] NOT ("Animals"[Mesh] AND "Humans"[Mesh])) NOT (editorial[ptyp] OR comment[ptyp] OR news[ptyp] OR letter[ptyp] OR review[ptyp] OR systematic review[ptyp] OR systematic review[ti] OR meta-analysis[ptyp] OR meta-analysis[ti] OR meta-analyses[ti] OR retracted publication[ptyp] OR retraction of publication[ptyp] OR retraction of publication[tiab] OR retraction notice[ti]) Filters: Publication date from 2000/01/01 to 2019/06/19; English

\section{Cochrane Central Register of Controlled Trials (CENTRAL)}

- Provider: John Wiley \& Sons

- Date(s) searched: June 19, 2019

- Date range searched: January 1, 2000-June 19, 2019

- Search Terms:

\#1 - [mh Meals] OR [mh Fasting] OR [mh "Feeding Behavior"]

\#2 - ("frequency of eating" OR "eating frequency" OR "feeding frequency" OR "meals per day" OR "beverage intake" OR "meal frequency" OR "meal timing" OR "meal time" OR mealtime* OR daily meal* OR dinnertime* OR "eating occasion*" OR "snack frequency" OR "snacking frequency" OR "intermittent fasting" OR "fasting diet" OR "alternate-day fasting" OR "meal skipping" OR "breakfast skipping" OR "skipping breakfast*" OR "drinking frequency" OR "infrequent consumption" OR "frequent consumption" OR "Feeding Behavior"[Mesh:NoExp] OR "feeding behavior" OR "eating pattern" OR "time restricted feeding" OR "meal profile*" OR "meal pattern"” OR chrono-nutrition OR "intermittent energy restriction" OR "eating time"): $: \mathrm{ti}, \mathrm{ab}, \mathrm{kw}$

\#3 - \#1 OR \#2

\#4 - [mh Mortality] OR [mh /MO]

\#5 - (mortality):ti,ab,kw 
\#6 - \#4 OR \#5

\#7 - \#3 AND \#6" with Publication Year from 2000 to 2019, in Trials (Word variations have been searched)

\section{Embase}

- Provider: Elsevier

- Date(s) searched: June 19, 2019

- Date range searched: January 1, 2000-June 19, 2019

- Search Terms:

\#1 - 'frequency of eating':ab,ti OR 'eating frequency':ab,ti OR 'feeding frequency':ab,ti OR 'meals per day':ab,ti OR 'beverage intake':ab,ti OR 'meal frequency':ab,ti OR 'meal timing':ab,ti OR 'meal time':ab,ti OR mealtime*:ab,ti OR 'daily meal' :ab,ti OR dinnertime*:ab,ti OR 'eating occasion $^{*}: a b, t i$ OR 'snack frequency':ab,ti OR 'snacking frequency':ab,ti OR 'intermittent fasting':ab,ti OR 'fasting diet*':ab,ti OR 'alternate-day fasting':ab,ti OR 'meal skipping':ab,ti OR 'breakfast skipping':ab,ti OR 'skipping breakfast ${ }^{\star \prime}: a b, t i$ OR 'drinking frequency':ab,ti OR 'infrequent consumption':ab,ti OR 'frequent consumption':ab,ti OR 'feeding behavior':ab,ti OR 'eating pattern': ab,ti OR 'time restricted feeding ${ }^{* '}: a b, t i$ OR 'meal profile':ab,ti OR 'meal pattern*':ab,ti OR 'chrono nutrition':ab,ti OR 'intermittent energy restriction*':ab,ti OR 'eating time ${ }^{* 1}: a b, t i$

\#2 - 'meal'/exp OR 'fasting'/exp OR 'feeding behavior'/exp

\#3 - \#1 OR \#2

\#4 - 'mortality'/exp

\#5 - mortality:ab,ti

\#6 - \#4 OR \#5

\#7 - \#3 AND \#6 AND ([article]/lim OR [article in press]/lim) AND [humans]/lim AND [english]/lim AND [2000-2019]/py NOT ([conference abstract]/lim OR [conference review]/lim OR [conference paper]/lim OR [editorial]/lim OR [erratum]/lim OR [letter]/lim OR [note]/lim OR [review]/lim OR [systematic review]/lim OR [meta analysis]/lim)

\section{LITERATURE SEARCH AND SCREENING RESULTS}

The flow chart (Figure 2) below illustrates the literature search and screening results for articles examining the systematic review question. The results of the electronic database searches, after removal of duplicates, were screened independently by two NESR analysts using a step-wise process by reviewing titles, abstracts, and full-texts to determine which articles met the inclusion criteria. Refer to Table $\mathbf{2}$ for the rationale for exclusion for each excluded full-text article. A manual search was done to find articles that were not identified when searching the electronic databases; all manually identified articles were also screened to determine whether they meet criteria for inclusion. 
Figure 2: Flow chart of literature search and screening results

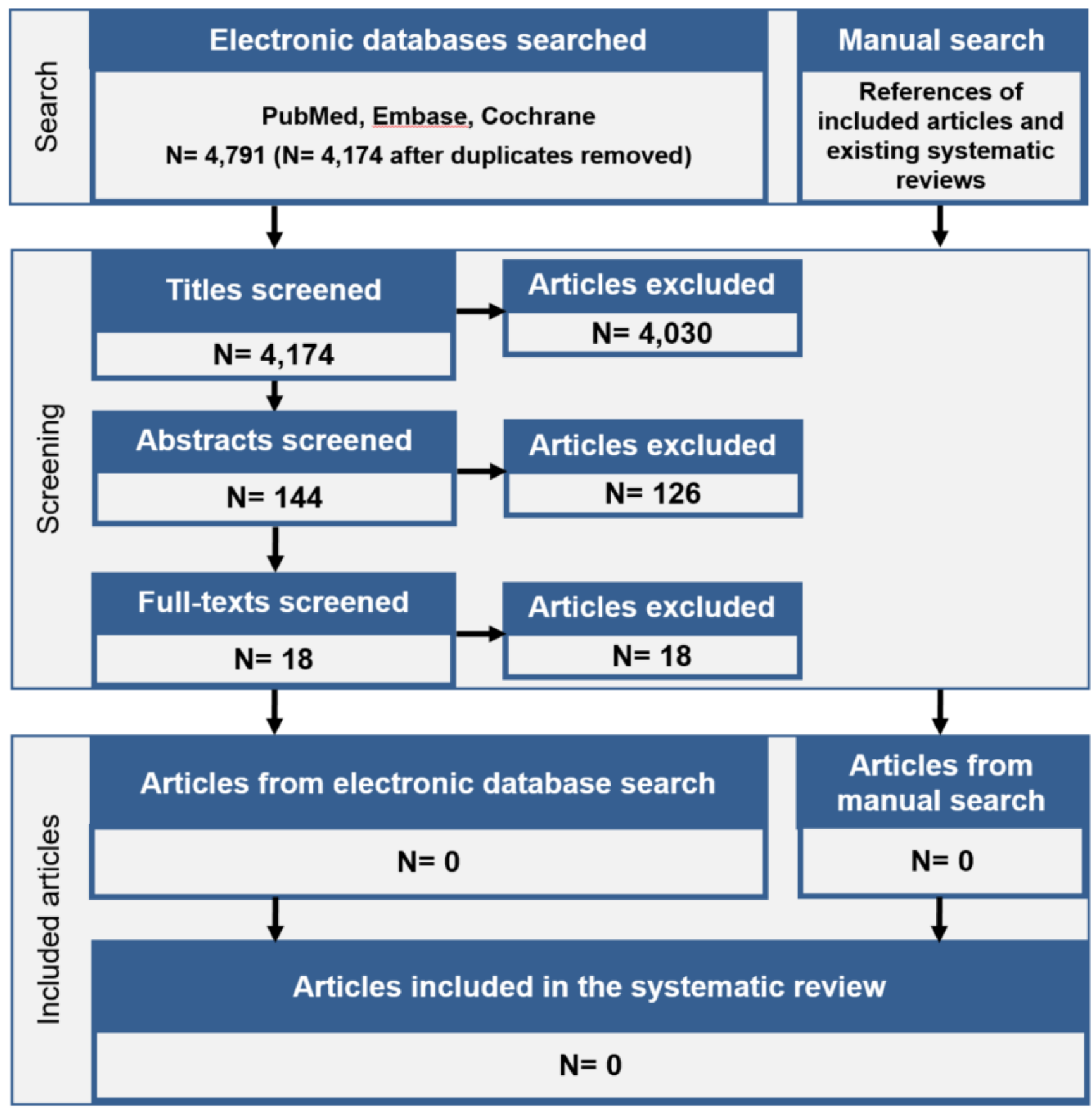




\section{Excluded articles}

The table below lists the articles excluded after full-text screening, and includes a column to document the rationale for study exclusion based on the criteria in Table 1. At least one reason for exclusion is provided for each article, though this may not reflect all possible reasons for exclusion. Information about articles excluded after title and abstract screening is available upon request.

\section{Table 2. Articles excluded after full text screening with rationale for exclusion}

\begin{tabular}{|c|c|c|}
\hline & Citation & Rationale \\
\hline 1 & $\begin{array}{l}\text { Rong, S, Snetselaar, LG, Xu, G, Sun, Y, Liu, B, Wallace, RB, Bao, W. Association of skipping breakfast with } \\
\text { cardiovascular and all-cause mortality. J Am Coll Cardiol. 2019. 73:2025-2032. } \\
\text { doi:10.1016/j.jacc.2019.01.065. }\end{array}$ & $\begin{array}{l}\text { Eating Frequency Data } \\
\text { Collection }\end{array}$ \\
\hline 2 & $\begin{array}{l}\text { Al Assaad, RG, Bachir, R, El Sayed, MJ. Impact of Ramadan on emergency department visits and on medical } \\
\text { emergencies. Eur J Emerg Med. 2018. 25:440-444. doi:10.1097/mej.0000000000000485. }\end{array}$ & Intervention/ Exposure \\
\hline 3 & $\begin{array}{l}\text { Pruimboom, L, Muskiet, FAJ. Intermittent living; the use of ancient challenges as a vaccine against the } \\
\text { deleterious effects of modern life - A hypothesis. Med Hypotheses. 2018. 120:28-42. } \\
\text { doi:10.1016/j.mehy.2018.08.002. }\end{array}$ & Study Design \\
\hline 4 & $\begin{array}{l}\text { Elbarsha, A, Elhemri, M, Lawgaly, SA, Rajab, A, Almoghrabi, B, Elmehdawia, RR. Outcomes and hospital } \\
\text { admission patterns in patients with diabetes during Ramadan versus a non-fasting period. Ann Saudi Med. } \\
\text { 2018. 38:344-351. doi:10.5144/0256-4947.2018.344. }\end{array}$ & Health Status \\
\hline 5 & $\begin{array}{l}\text { Cummings, JR, Mason, AE, Puterman, E, Tomiyama, AJ. Comfort eating and all-cause mortality in the US } \\
\text { Health and Retirement Study. Int J Behav Med. 2018. 25:473-478. doi:10.1007/s12529-017-9706-8. }\end{array}$ & Intervention/ Exposure \\
\hline 6 & $\begin{array}{l}\text { Loprinzi, PD, Addoh, O, Mann, JR. Association between dietary behavior and mortality among American } \\
\text { adults with mobility limitations. Disabil Health J. 2018. 11:126-129. doi:10.1016/j.dhjo.2017.05.006. }\end{array}$ & Intervention/ Exposure \\
\hline 7 & $\begin{array}{l}\text { Lengyel, CO, Jiang, D, Tate, RB. Trajectories of nutritional risk: The Manitoba Follow-Up Study. J Nutr Health } \\
\text { Aging. 2017. 21:604-609. doi:10.1007/s12603-016-0826-7. }\end{array}$ & $\begin{array}{l}\text { Intervention/ Exposure, } \\
\text { Outcome }\end{array}$ \\
\hline 8 & $\begin{array}{l}\text { Chen, HJ, Wang, Y, Cheskin, LJ. Relationship between frequency of eating and cardiovascular disease } \\
\text { mortality in U.S. adults: the NHANES III follow-up study. Ann Epidemiol. 2016. 26:527-533. } \\
\text { doi:10.1016/j.annepidem.2016.06.006. }\end{array}$ & $\begin{array}{l}\text { Eating Frequency Data } \\
\text { Collection }\end{array}$ \\
\hline 9 & $\begin{array}{l}\text { Dai, J, Krasnow, RE, Reed, T. Midlife moderation-quantified healthy diet and 40-year mortality risk from CHD: } \\
\text { the prospective National Heart, Lung, and Blood Institute Twin Study. Br J Nutr. 2016. 116:326-34. } \\
\text { doi:10.1017/s0007114516001914. }\end{array}$ & Intervention/ Exposure \\
\hline
\end{tabular}


10 Menotti, A, Puddu, PE, Maiani, G, Catasta, G. Cardiovascular and other causes of death as a function of lifestyle habits in a quasi extinct middle-aged male population. A 50-year follow-up study. Int J Cardiol. 2016. 210:173-8. doi:10.1016/j.jijcard.2016.02.115.

11 Yokoyama, Y, Onishi, K, Hosoda, T, Amano, H, Otani, S, Kurozawa, Y, Tamakoshi, A. Skipping breakfast and risk of mortality from cancer, circulatory diseases and all causes: findings from the Japan Collaborative Cohort Study. Yonago Acta Med. 2016. 59:55-60.

12 Zhou, T, Li, X, Tang, Z, Xie, C, Tao, L, Pan, L, Huo, D, Sun, F, Luo, Y, Wang, W, Yan, A, Guo, X. Risk factors of CVD mortality among the elderly in Beijing, 1992 - 2009: an 18-year cohort study. Int J Environ Res Public Health. 2014. 11:2193-208. doi:10.3390/ijerph110202193.

13 Capewell, S, O'Flaherty, M. Rapid mortality falls after risk-factor changes in populations. Lancet. 2011. 378:752-3. doi:10.1016/s0140-6736(10)62302-1.

Eating Frequency Data Collection

Intervention/ Exposure

\begin{tabular}{llc}
\hline 14 & $\begin{array}{l}\text { Bener, A, Hamad, A, Fares, A, Al-Sayed, HM, Al-Suwaidi, J. Is there any effect of Ramadan fasting on stroke } \\
\text { incidence?. Singapore Med J. 2006. 47:404-8. }\end{array}$ & Outcome, Health Status \\
\hline 15 & $\begin{array}{l}\text { Velten, APC, Cade, NV, Silva, GAE, Oliveira, ERA. Profile of mortality from external causes among Seventh- } \\
\text { day Adventists and the general populations. Ciencia \& saude coletiva. 2017. 22:2375-2382. } \\
\text { doi:10.1590/1413-81232017227.13792015. }\end{array}$ & Intervention/ Exposure \\
& $\begin{array}{l}\text { Beck, AM. Weight loss, mortality and associated potentially modifiable nutritional risk factors among nursing } \\
\text { home residents - A Danish follow-up study. Journal of Nutrition, Health and Aging. 2014. 19:96-101. } \\
\text { doi:10.1007/s12603-015-0439-6. }\end{array}$ & Intervention/ Exposure \\
\hline 16 & $\begin{array}{l}\text { Giles, GG, English, DR. The Melbourne Collaborative Cohort Study. IARC scientific publications. 2002. } \\
\text { 156:69-70. }\end{array}$ & Study Design, \\
& $\begin{array}{l}\text { Intervention/ Exposure } \\
\text { Lopez-Legarrea, P, De la Iglesia, R, Abete, I, Ibanez-Melo, A, Navas-Carretero, S, Bondia-Pons, I, Forga, L, }\end{array}$ & Study Design, \\
& $\begin{array}{l}\text { Zulet, M, Martinez, A. The Resmena diet: a new effective dietary strategy for reducing metabolic syndrome. } \\
\text { Obesity facts. 2012. 5:230-231. doi:10.1159/000258190. }\end{array}$ \\
\hline 18
\end{tabular}

